Sharif University of Technology
Scientia Iranica
Transactions E: Industrial Engineering
SCIENTIA

\title{
Government subsidies in manufacturing and remanufacturing with consumer segment and heterogeneous demand
}

\author{
L. Xu ${ }^{a, b, *}$, Q. Peng ${ }^{c}$, J. Chen ${ }^{a}$, and Ch. Wang ${ }^{c}$ \\ a. College of Transport and Communications, Shanghai Maritime University, Shanghai 201306, China. \\ b. Antai College of Economics and Management, Shanghai Jiaotong University, Shanghai, China. \\ c. School of Economics and Management, Shanghai Maritime University, Shanghai 201306, China.
}

Received 18 February 2019; received in revised form 22 April 2019; accepted 12 October 2019

\author{
KEYWORDS \\ Manufacturing and \\ remanufacturing; \\ Government subsidy; \\ Consumer segment; \\ Heterogeneous \\ demand.
}

\begin{abstract}
Waste products have dual properties; environmental hazards and resource recovery, while recycling behavior has a greater positive external economic effect, which often results in less enthusiasm for enterprises to engage in remanufactured activity. For price decisions on whether a government should subsidize a closed-loop supply chain or not, a Stackelberg game model was constructed under three scenarios: 1) none are subsidized (Model N), 2) subsidize the manufacturer (Model M), and 3) subsidize the recycler (Model $\mathrm{R}$ ). This is in order to obtain the optimal government subsidy and decisions regarding costs, as well as to analyze the difference between the equilibrium of the three scenarios. It has been concluded that a government subsidy improves social welfare, as well as a government implementation of different subsidy policies based on the need for economic and social progress.
\end{abstract}

(C) 2021 Sharif University of Technology. All rights reserved.

\section{Introduction}

In recent years, environmental pollution and lack of resources are constantly highlighted all over the world, which makes creation of new energy vehicles of increasing concern and which are being promoted by society. It is conducive to further improve energy efficiency, reduce greenhouse gas emissions, and promote energy conservation and emission reduction [1]. According to "energy saving and new energy automotive industry development (2012-2020)" issued by China, the cumulative production and sale of pure electric vehicles and plug-in hybrid vehicles were to be over 5 million by 2020. Relevant data forecast the cumulative amount of

*. Corresponding author. Tel./Fax: +862138282463 E-mail address: xulang@shmtu.edu.cn (L. Xu)

doi: $10.24200 /$ sci. 2019.50493 .1724 discarded Chinese pure electric passenger cars, and hybrid passenger power batteries were to reach 120,000 170,000 tons by around 2020. Thus, the recycling and reuse new energy vehicle power batteries have become a problem which cannot be ignored. Usually, the life of a lithium battery is about 20 years, but for new energy vehicles, it can only be used for 3-5 years before being scrapped. Because the capacity decays to the initial capacity of $80 \%$ or less, electric car mileage is significantly reduced, and the battery must be replaced. From the current situation in Europe and the United States, some manufacturers are vigorously promoting the use of battery recycling research to develop technology for large-scale commercial recycling [2,3]. For example, Umicore developed ultra-high temperature technology to recycle waste batteries. An American company, in the opposite direction to the former, uses liquid nitrogen in an ultra-low temperature environment for batteries for processing, so that chemical properties 
become inactive. Germany, which has no battery manufacturers, is also working to study the recycling network system. It is known that current power battery research in China is mainly focused on improving safety performance and service life, and, for recycling, is very scarce, or even seriously out of date. In power batteries, a lithium battery contains mercury, cadmium, lead and other large amounts of toxic heavy metal elements. Its positive and negative materials, electrolyte solutions and other substances also have a considerable impact on the environment. Indeed, the tens of thousands of tons of waste produced per year is a great problem for the future. With the overall rise in the demand for electric vehicles, lithium will be in short supply in the future. Thus, recycling and remanufacturing, as an effective way to achieve the recycling of resources, are cost-saving and sales-revenue-satisfying, which is, thus, conducive to establishing a recycling economy to achieve economic and environmentally sustainable development.

At the present stage of recycling and remanufacturing, the recycling method of used products mainly includes the value-added method (such as remanufacturing, refurbishment and repairing) and the material recycling method (such as dismantling and recycling). In the treatment of waste lithium batteries, it is necessary for them to be pretreated, including discharge, dismantling and the iron shell after dismantling. The electrode material must also be treated, such as alkali leaching, acid leaching, and extraction after various procedures. However, complex recycling procedures and technology development make many recycling companies reluctant to participate. Government subsidies, as a powerful tool to stimulate domestic demand and promote a circular economy, play an increasingly important role in the decisionmaking of Closed-Loop Supply Chain (CLSC). In developed countries, remanufacturing research has been given permanent tax credits and a detailed subsidy support policy has been developed. Compared with developed countries, China has promulgated a relevant subsidy policy for electrical and electronic production waste, taking automotive engines, gearboxes and other remanufactured products as pilot financial subsidies. However, in the actual implementation process, due to different designs in the subsidy model and government subsidy objects, the impact of the difference in CLSC operation efficiency is very significant. The question of how much subsidy should be given, who should obtain the subsidy, and how the government should implement the subsidy to optimize the operation of the CLSC are urgent matters to be settled.

Although many researchers have focused on government subsidies [4-6], there is limited analysis focusing on the CLSC, especially considering consumer need and heterogeneous demand. To fill this gap, this paper aims to investigate optimal decisions for the government and the CLSC. The main contributions of this research are summarized as follows:

- Constructing the Stackelberg game models consisting of government, manufacturer and recycler, concerning consumer and heterogeneous demands;

- Deriving optimal decisions and analyzing the impact of relevant parameters on demand in the benchmark model;

- Proposing and comparing three kinds of subsidy model carried out by the government, and exploring the maximization of social welfare.

The rest of this paper is organized as follows. After reviewing the relevant literature in Section 2, the model description and assumption is introduced in Section 3. Section 4 solves the benchmark model to obtain optimal decisions without government subsidy. Section 5 presents the equilibrium and compares the difference of optimal results among three models. Additional numerical analysis is shown in Section 6, which is given by the conclusion in Section 7 .

\section{Literature review}

In recent years, many scholars have researched the CLSC with heterogeneous demands and government subsidy policies. This section will summarize the existing studies from three points.

\subsection{Consumer preference}

Recently, consumer preference plays a significant role in supply chain management [7]. Chen et al. (2017) [8] demonstrated the price and quality decisions in a dual-channel supply chain to show the effects of introducing a new channel on performance. Feng et al. (2017) [9] incorporated consumer behavior into modeling the reverse supply chain for dual-recycling, and investigated the optimal channel choice of different scenarios. Ji et al. (2017) [10] introduced members' emission reduction and consumer preferences into the supply chain decision, as well as comparing the optimal results between single and joint emission reduction. $\mathrm{Li}$ et al. (2016) [11] extended the green supply chain with channel substitution and green preference, as well as designing a two-tariff contract to coordinate the optimal decision. He et al. (2016) [12] studied the pricing and emission reduction decision in a CLSC with price- and emission-dependent demand, and evaluated the impact of consumer behavior on a CLSC. $\mathrm{Li}$ and $\mathrm{Li}$ (2016) [13] analyzed optimal sustainability degree and profit based on product sustainability and consumer preference. Differentiation of consumer preference on new and remanufactured products is significant. Ferguson and Swaminathan (2006) [14] introduced the 
collection function to analyze the diverse price strategies of the new manufactured product and remanufactured product with the heterogeneous consumer group. Debo et al. (2005) [15] introduced an oligarchic manufacturer into remanufacturing behavior and analyzed the technology choice based on the remanufactured preference. Atasu et al. (2008) [16] divided the market into common and environmental consumers, considering different consumer willingness to pay for new and remanufactured products. Thus, some researchers carried out a study on the decisions of a CLSC via consideration of the consumer remanufacturing preference. Shu et al. (2017) [17] formulated a Stackelberg game model of a CLSC where consumers may or may not be willing to pay a remunerative price for remanufactured products. In addition, Atefeh et al. (2018) [18] explored a new approach regarding the design of a network of a CLSC via emphasizing the impact of government environmental policies based on a bi-level mixed integer linear programming model. Further, Nazari et al. (2018) [19] used game theory to determine ordering and pricing policies in a single-period CLSC, as well as designing a return policy to coordinate the members. This research differs in two aspects from the abovementioned literature. This paper seeks to discover the optimal decision of carbon emission reduction and develop a two-period decision model in a CLSC, which is absent in existing papers. Moreover, the difference between new and remanufactured products is identified based on consumer preference.

\subsection{Closed-Loop Supply Chain (CLSC)}

The next issue includes a CLSC, focusing on recycling and remanufacturing. Savaskan et al. (2004) [20] found that the joint recycling model has maximum social profits, and the model of retailer recycling is superior to the other models regarding the two-echelon supply chain. Ferrer and Swaminathan (2006) [14] compared the manufacturer's decision under the different models and discovered that the reason why a manufacturer would decrease the price is to increase market sales including remanufactured products. Mitra and Webster (2008) [21] focused on competition between the manufacturer and retailer in a two-period game and analyzed the impact of different models on the member's responsibility and decision making. Xiong et al. (2013) [22] analyzed a CLSC consisting of one-single supplier and manufacturer, which showed that when the costs of new and remanufactured products are quite different, double marginalization will increase and the operational performance of the system would decrease. Although the decision models of the close-loop supply chain are developed in the above literature, consumer preference for remanufacturing, and the market segment have been ignored in previous research.

\subsection{Government subsidy}

Recycling of used products is a social systematic issue involving various factors, in which the government's role is significant [23]. Hafezalkotob (2015) [24] analyzed the optimal subsidy equilibrium of three government policies based on the competition of supply chains, as well as obtaining specific boundaries for maximizing environmental protection and profit seeking. Shao et al. (2017) [25] analyzed electric and gasoline vehicle markets under two different structures, as well as taking social welfare into account, maximizing government participation. Mitra et al. (2008) [21] analyzed the two-period game model of manufacturer and remanufacturer, and discovered that government subsidy promotes remanufacturing activity with increased member profit. Ma et al. (2013) [26] introduced the government consumption-subsidy to the decisions of a dual-channel supply chain considering heterogeneous demands, and analyzed the impacts of subsidy on government performance. Liu et al. (2016) [27] developed a price and quality competition model between formal and informal collecting channels, then examined the impact of consumer preference and government subsidy on the decisions of the supply chain. Shao et al. (2017) [25] proposed a two-stage game model of optimal price and performance level considering government subsidy, and providing suggestions for governments to firstly subsidize the high energy consumption industry; also that different industries should be differentiated. Heydari et al. (2017) [4] extended a two-echelon reverse and CLSC decision and coordination model to analyze the impact of consumer willingness and government intervention. Hong and Ke (2011) [28] determined optimal recycling fees, sales quantities and government subsidies in a reverse supply chain, in regard to maximizing both company profit and social welfare. The study mentioned above makes great contributions to the theoretical research of the CLSC, but still has shortcomings, as follows: Firstly, taking the government subsidy as the exogenous variable in the CLSC game model to make decisions, which did not conduct detailed research, propounds how the government makes the subsidy policy. Secondly, most current studies are based on the assumption that the subsidy object can be the consumer. After analyzing the influence of government on the supply chain enterprise, it is found that the subsidy object can also be the manufacturer or recycler.

Similar to Wang et al., (2014) [29], for price decisions on whether the government should subsidize the CLSC or not, this paper established the Stackelberg model under three scenarios:

1. None are subsidized (Model N);

2. The manufacturer is subsidized (Model M);

3. The recycler is subsidized (Model R). 
In order to obtain the optimal government subsidy and price decision, as well as analyze the difference between the equilibrium of the three scenarios. Also, with analyses and comparison, suggestions are proposed for governments and enterprises, which can optimize the efficiency of the CLSC.

\section{Model description and assumptions}

This paper considers a CLSC consisting of one-single manufacturer and one-single retailer under the condition of government subsidy (the framework is shown in Figure 1). For simplicity, superscripts " $n$ " and " $r$ " are used to denote the new and remanufactured products, as well as the subscripts " $n$ " and " $r$ " to denote the primary and replacement consumers. Thus, consumers have different preferences to new and remanufactured products. In this structure, the recycler collects the obsolete products from the replacement consumers with the recycling price $b$ and processes them to the manufacturer with the trading price $p_{0}$. Meanwhile, the manufacturer produces the new and remanufactured products with the selling pricing $p_{n}, p_{r}$.

To establish the decision model of the government and the CLSC, the following assumptions are considered to simplify the research and highlight its purpose, as follows:

Assumption 1. In the market, there are two types of consumer: the primary and replacement consumers. The primary consumers do not have an obsolete product and can directly purchase new or remanufactured products, while the replacement consumers who own the obsolete products must return them to the recycler before purchasing a product. During a certain period, the ratios of the primary and replacement consumers are assumed as $\alpha$ and $1-\alpha$, where $0 \leq \alpha \leq 1$.

Assumption 2. In reality, the obsolete products can be used for remanufacturing, and their values are equal for the recycler. For simplicity, this paper considers the obsolete products are homogeneous. Compared with the new product, the manufactured product has advantages such as low energy-consumption and costproduction [30]. Therefore, the cost of a remanufactured unit product is lower than that of a new product, namely: $0<p_{0}+c_{r}<c_{n}$. Meanwhile, it is assumed that $\Delta=c_{n} / c_{r}$ represents the cost difference between new and remanufactured products, where $c_{n}$ and $c_{r}$ denote the production costs for new and remanufactured products, respectively.

Assumption 3. For the consumers who play an important role in the market, the primary and replacement consumers have two purchase options; a new product or a remanufactured product. In this paper, the consumer segment and heterogeneous demand are considered, thus, the primary and replacement consumers make the purchase decision according to the utilities of different products after observing the selling price and recycling price $[14,15,31]$. Hence, the primary consumers who purchase the new and remanufactured product get utility:

$$
\begin{aligned}
& U_{n}^{n}=\theta-p_{n}, \\
& U_{n}^{r}=\delta \theta-p_{r} .
\end{aligned}
$$

However, the recycler collects obsolete products from the replacement consumers with $b$ to purchase the new and remanufactured product. The replacement consumers purchasing the new and remanufactured product get utility

$$
\begin{aligned}
& U_{r}^{n}=\theta-p_{n}+b, \\
& U_{r}^{r}=\delta \theta-p_{r}+b,
\end{aligned}
$$

where the consumer's valuation of the new product, denoted by $\theta$, follows uniform distribution on the interval $[0,1]$, and $\delta$ means the valuation discount of consumers to purchase remanufactured products, satisfying $0<\delta<1$.

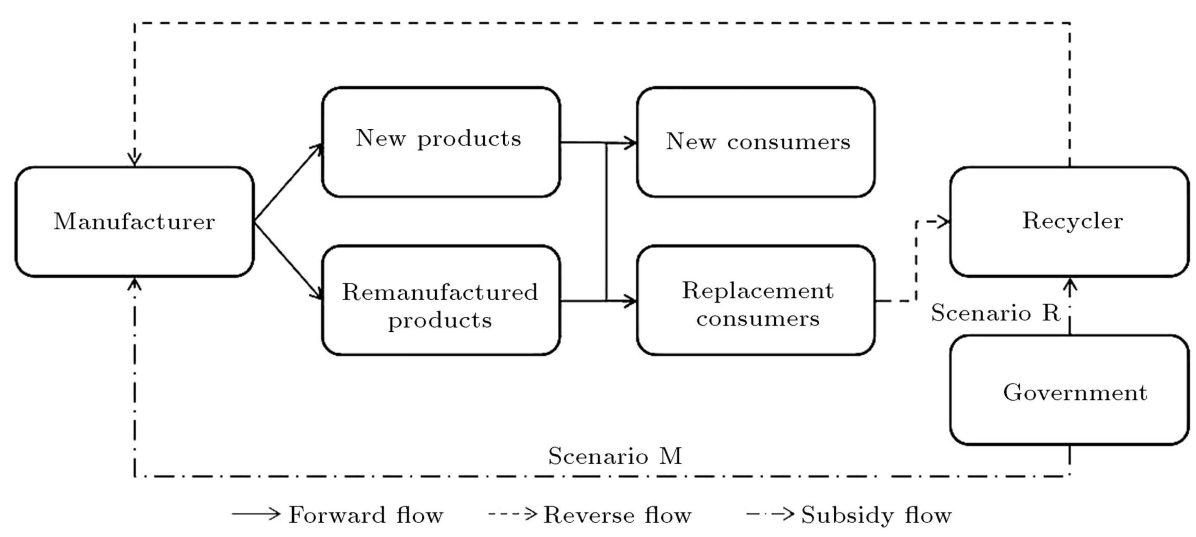

Figure 1. Closed-loop supply chain model under different government subsidies. 
Assumption 4. Drawing from the previous literature about government policies [24,32], it is established that the objective function of a government is to develop recycling industries, and a government's subsidy policy aims to maximize social welfare, consisting of total profit, consumer surplus and government expenditure. Thus, the function for governmental maximization is asserted, considering the profit of supply chain $\pi_{s c}(s)$, the utility of consumer $C S$ and government expenditure $g(s)$, which can be represented as:

$$
\begin{array}{ll}
\max & \pi_{g}=\pi_{s c}(s)+C S-g(s), \\
\text { s.t.: } & s \geq 0 .
\end{array}
$$

Assumption 5. While the government, manufacturer and retailer are respectively optimizing their own goals, they have access to asymmetric information and decisions are considered in a single period. To establish the Stackelberg model among government and supply chain members, it is assumed that the government has sufficient power over the manufacturer and the retailer as the leader. With a similar assumption used by Savaskan et al. (2004) [20], the manufacturer uses its foresight into the recycler's reaction before making the optimal selling decisions.

\section{Benchmark model: The government does not subsidize CLSC}

In this section, the manufacturer provides new and remanufactured products to the primary and replacement consumers, as well as being responsible for the collection of obsolete products. Before analyzing the game between the manufacturer and retailer in the CLSC, the new and remanufactured demands for primary and replacement consumers are discussed via comparing the value of the utilities to decide which product to buy. According to the above assumptions, the following is obtained:

1. When $U_{n}^{n}>U_{n}^{r}$ and $U_{n}^{n}>0$, the primary consumers with a valuation in the interval prefer to purchase new products. In this case, the demand of the new product for the primary consumers is:

$$
q_{n}^{n}=\alpha \cdot \int_{\left(p_{n}-p_{r}\right) /(1-\delta)}^{1} d \theta=\alpha\left(1-\frac{p_{n}-p_{r}}{1-\delta}\right)
$$

2. When $U_{r}^{n}>U_{r}^{r}$ and $U_{r}^{n}>0$, replacement consumers with a valuation in the interval prefer to purchase new products. In this case, the demand of the new product for the replacement consumers is:

$$
q_{r}^{n}=(1-\alpha) \int_{\left(p_{n}-p_{r}\right) /(1-\delta)}^{1} d \theta=(1-\alpha)\left(1-\frac{p_{n}-p_{r}}{1-\delta}\right)_{(8)}
$$

3. When $U_{n}^{n}<U_{n}^{r}$ and $U_{n}^{r}>0$, the new consumers with a valuation in the interval prefer to purchase remanufactured products. In this case, the demand of the remanufactured product for the primary consumers is:

$$
q_{n}^{r}=\alpha \cdot \int_{p_{r} / \delta}^{\left(p_{n}-p_{r}\right) /(1-\delta)} d \theta=\alpha\left(\frac{p_{n}-p_{r}}{1-\delta}-\frac{p_{r}}{\delta}\right)
$$

4. When $U_{n}^{n}<U_{n}^{r}$ and $U_{n}^{r}>0$, the replacement consumers with a valuation in the interval prefer to purchase the remanufactured products. In this case, the demand of the remanufactured product for the replacement consumer is:

$$
\begin{aligned}
q_{r}^{r} & =(1-\alpha) \int_{\left(p_{r}-b\right) / \delta}^{\left(p_{n}-p_{r}\right) /(1-\delta)} d \theta \\
& =(1-\alpha)\left(\frac{p_{n}-p_{r}}{1-\delta}-\frac{p_{r}-b}{\delta}\right) .
\end{aligned}
$$

Through the above analysis of different choice behaviors, the necessary conditions of new and remanufacturing demands for the new and primary consumers are obtained. Therefore, the following case is defined as Scenario N. According to Miao et al. (2018) [33], simple assumptions $\delta p_{n} \geq p_{r}$ and $\delta p_{n}-p_{r}+b(1-$ $\delta) \geq 0$ are made that guarantee that the demand of new and remanufactured products is greater than zero. Because the manufacturer and retailer are the leader and follower in the Stackelberg game, the game sequence is characterized as follows: First, the manufacturer determines the wholesale price and recycling price, while the retailer determines the selling price to the consumers based on the best response of the manufacturer. Thus, the manufacturer and retailer profit functions are, respectively:

$$
\begin{aligned}
\pi_{m}^{N}= & \left(p_{n}-c_{n}\right)\left(q_{n}^{n}+q_{r}^{n}\right)+\left(p_{r}-c_{r}\right)\left(q_{n}^{r}+q_{r}^{r}\right) \\
& -p_{0}\left(q_{r}^{n}+q_{r}^{r}\right) \\
\pi_{r}^{N}= & \left(p_{0}-b\right)\left(q_{r}^{n}+q_{r}^{r}\right) .
\end{aligned}
$$

Proposition 1. In Scenario $N$, the optimal decisions for the manufacturer and retailer can be summarized as follows: 


$$
\begin{aligned}
& p_{n}^{N}=\frac{1}{2}\left[1+c_{n}+\frac{2 p_{0}(1-\alpha)}{1+\alpha}\right], \\
& p_{r}^{N}=\frac{1}{2}\left[\delta+c_{r}+\frac{2 p_{0}(1-\alpha)}{1+\alpha}\right], \\
& b^{N}=\frac{1}{4}\left[-\delta+c_{r}+\frac{4 p_{0}}{1+\alpha}\right] .
\end{aligned}
$$

Proof. The Stackelberg game is solved with backward induction to guarantee optimal decisions. According to the second order partial derivative of the retailer's profit, $\pi_{r}^{N}$, with respect to $b$, is $\partial^{2} \pi_{r}^{N} / \partial b^{2}=-2(1-$ $\alpha) / \delta<0$. From the concavity of the recycler's profit, $\pi_{m}^{N}$ is strictly a concave function with $b$. Hence, solving the first-order condition by setting to zero, the optimal recycling price is obtained. Then, the best response for the recycler's decision can be determined as $\bar{b}=\left(-\delta+p_{0}+p_{r}\right) / 2$. Given the recycler's response to the recycling price, the manufacturer decides the selling prices of new and remanufactured products to maximize profit. Then, the determinant of the Hessian matrix can easily be obtained based on the second order partial derivative of the manufacturer's profit, $\pi_{m}^{N}$, with respect to $p_{n}$ and $p_{r}$, as follows:

$$
\begin{aligned}
H\left(p_{n}, p_{r}\right) & =\left[\begin{array}{cc}
\frac{\partial^{2} \pi_{m}^{N}}{\partial p_{n}^{2}} & \frac{\partial^{2} \pi_{m}^{N}}{\partial p_{n} \partial p_{r}} \\
\frac{\partial^{2} \pi_{m}^{N}}{\partial p_{r} \partial p_{n}} & \frac{\partial^{2} \pi_{m}^{N}}{\partial p_{r}^{2}}
\end{array}\right] \\
& =\left[\begin{array}{cc}
-\frac{2}{1-\delta} & \frac{2}{1-\delta} \\
\frac{2}{1-\delta} & -\frac{1+\alpha+\delta(1-\delta)}{\delta(1-\delta)}
\end{array}\right]=\frac{2(1+\alpha)}{\delta(1-\delta)}>0
\end{aligned}
$$

From the concavity of the Hessian matrix, the profit function of manufacturer $\pi_{m}^{N}$ is jointly concave in $p_{n}$ and $p_{r}$. Hence, solving the first-order condition by setting to zero, the optimal selling prices of new and remanufactured products can be obtained. Then, substituting the optimal values of $p_{n}$ and $p_{r}$ in the response function of the recycler, we can get the optimal values of $b$.

In this scenario, the optimal decisions for the manufacturer and retailer are derived from the Stackelberg game. For the utility of new and primary consumers, the new demands are obtained, respectively, as:

$$
\begin{aligned}
& q_{n}^{n}=\frac{\alpha\left(1-\delta-c_{n}+c_{r}\right)}{2(1-\delta)}, \\
& q_{r}^{n}=\frac{(1-\alpha)\left(1-\delta-c_{n}+c_{r}\right)}{2(1-\delta)},
\end{aligned}
$$

and the remanufacturing demands are, respectively:

$$
\begin{aligned}
& q_{n}^{r}=\frac{\alpha\left[(1+\alpha)\left(\delta c_{n}-c_{r}\right)-\alpha p_{0}(1-\delta)(1-\alpha)\right]}{2 \delta(1-\delta)(1-\alpha)} \\
& q_{r}^{r}= \\
& \frac{\alpha\left\{(1+\alpha)\left[\left(2 \delta c_{n}-(1+\delta) c_{r}\right)\right]+(1-\delta)\left[4 \alpha p_{0}-\delta(1+\alpha)\right]\right\}}{4 \delta(1-\delta)(1-\alpha)}
\end{aligned}
$$

Corollary 1. The recycling price, and the selling price of new and remanufactured products decrease with a rise in $\alpha$, whereas, they increase with a rise in $p_{0}$.

Proof. The first-order partial derivative of the selling price and the recycling price, with respect to the proposition of the primary consumer, give:

$$
\begin{aligned}
& \partial p_{n}^{n} / \partial \alpha=\partial p_{r}^{n} / \partial \alpha=-2 p_{0} /(1+\alpha)^{2} \leq 0 \\
& \partial b^{N} / \partial \alpha=-p_{0} /(1+\alpha)^{2} \leq 0 .
\end{aligned}
$$

Meanwhile, the first-order partial derivative of the selling price and the recycling price, with respect to the trading price of the remanufactured product, give:

$$
\begin{aligned}
& \partial p_{n}^{n} / \partial p_{0}=\partial p_{r}^{n} / \partial p_{0}=(1-\alpha) /(1+\alpha) \geq 0, \\
& \partial b^{N} / \partial \alpha=1 /(1+\alpha) \geq 0 .
\end{aligned}
$$

According to Corollary 1, the selling and recycling price mainly depend on the production cost, the trading price of the obsolete product and the ratios of the primary consumer. The selling price and recycling price decrease with a rise in the trading price of the obsolete product, and increase with a rise in the ratios of the primary consumer. Hence, it is necessary for enterprises to adopt the low price strategy for capturing the market demand of new and remanufactured products. Additionally, when the ratio of the primary consumer is low, the recycling quantity from the replacement consumer is not very high and the consumers are willing to keep using the old product. Thus, it is necessary for the government to determine an appropriate subsidy to develop the recycling economy.

Corollary 2. The new demands for primary and replacement consumers decrease with the rise in $\Delta$ and $\delta$; however the remanufactured demands for the primary consumer and the replacement consumer increase with the rise in $\Delta$ and $\delta$.

Proof. The first-order partial derivative of the new demands for primary and replacement consumers, with respect to the difference in production costs and remanufactured preferences, is given as: 


$$
\begin{aligned}
& \partial q_{n}^{n} / \partial \Delta=-\alpha c_{r} / 2(1-\delta) \leq 0, \\
& \partial q_{r}^{n} / \partial \Delta=-c_{r}(1-\alpha) / 2(1-\delta) \leq 0, \\
& \partial q_{n}^{n} / \partial \delta=-\alpha\left(c_{n}-c_{r}\right) / 2(1-\delta)^{2} \leq 0, \\
& \partial q_{r}^{n} / \partial \delta=-(1-\alpha)\left(c_{n}-c_{r}\right) / 2(1-\delta)^{2} \leq 0 .
\end{aligned}
$$

Meanwhile, the first-order partial derivative of the remanufactured demands for primary and replacement consumers, with respect to the difference in production costs and remanufactured preferences, is given as:

$$
\begin{aligned}
& \partial q_{n}^{r} / \partial \Delta=\alpha c_{r} / 2(1-\delta)(1-\alpha) \geq 0 \\
& \partial q_{r}^{r} / \partial \Delta=\alpha c_{r}(1-\alpha) / 2(1-\delta)(1-\alpha) \geq 0 \\
& \partial q_{n}^{r} / \partial \delta=\alpha\left[p_{0}(1-\alpha)(1-\delta)^{2}\right. \\
& \left.\quad+(1+\alpha)\left(\delta c_{n}-c_{r}\right)\right] / \delta^{2}(1-\alpha)(1-\delta)^{2} \geq 0 \\
& \partial q_{r}^{r} / \partial \delta=\alpha\left[4 \alpha p_{0}(1-\alpha)(1-\delta)^{2}\right. \\
& \left.\quad+(1+\alpha)\left(2 \delta^{2} c_{n}-c_{r}\right)\right] / 4 \delta^{2}(1-\alpha)(1-\delta)^{2} \geq 0 .
\end{aligned}
$$

According to Corollary 2, the new demand for primary and replacement consumers decreases with the difference in production costs and remanufactured preferences. The remanufactured demand increases with the difference in production costs and remanufactured preferences. It means that the output of new products will replace that of remanufactured products with the rising production costs of remanufactured products. However, with the rising remanufactured preference, the output of new products will increase, while that of remanufactured products drops. This is done to maintain maximization of profits based on production and consumer preferences. Meanwhile, the government should encourage manufacturers and recyclers to develop recycling economies through subsidy policies.

\section{Government subsidy mechanisms to CLSC}

From the perspective of government, promoting a circular economy is an inevitable choice for sustainable development. In this section, the paper analyzes two kinds of subsidy mechanism via the manufacturer and recycler based on a benchmark model. This is in order to establish a three-period game theory CLSC model between the government, the manufacturer and the recycler to obtain optimal equilibrium, as well as to discuss the impact of subsidy policies on the decisions and profits of the supply chain. According to the Stackelberg game, the model ensures perfect subgame equilibrium obtained from sequential games as follows: in the first stage, the government determines the optimal subsidy decision based on the maximization of social welfare. During the second stage, the manufacturer decides the selling prices for new and remanufactured products, given the best response of the government. At the third stage, the recycler determines the recycling price of obsolete products from replacement consumers.

\subsection{Model M: The government provides a subsidy to the manufacturer}

To encourage manufacturers to participate in a collective activity is an effective method to improve the efficiency of a CLSC. For example, China proposed the WEEE (waste electrical and electronic products) Collection of Management Practice Fund on July, 2012 to solve remanufacturing technical difficulties $[5,34]$. The method for subsidizing recycling not only makes the collection cost more flexible, but also reduces management costs in a CLSC. In this subsection, a government subsidy model is provided to the manufacturer in accordance with the amount of obsolete products. Therefore, under the scenario of subsidizing the manufacturer, the profits of the manufacturer and the recycler can be presented as follows:

$$
\begin{aligned}
\pi_{m}^{M}= & \left(p_{n}-c_{n}\right)\left(q_{n}^{n}+q_{r}^{n}\right)+\left(p_{r}-c_{r}+s_{m}\right)\left(q_{n}^{r}+q_{r}^{r}\right) \\
& -p_{0}\left(q_{r}^{n}+q_{r}^{r}\right) \\
\pi_{r}^{M}= & \left(p_{0}-b\right)\left(q_{r}^{n}+q_{r}^{r}\right) .
\end{aligned}
$$

Proposition 2. In Model $M$, the optimal decision for the government subsidy is summarized by Eq. (27) as shown in Box I.

Proof. As shown in the proof above, the best response functions of the manufacturer and recycler are:

$$
\begin{aligned}
& p_{n}^{M}\left(s_{m}\right)=p_{n}^{N}, \quad p_{r}^{M}\left(s_{m}\right)=p_{r}^{N}-s_{m} / 2, \\
& b^{M}\left(s_{m}\right)=b^{N}-s_{m} / 2 .
\end{aligned}
$$

Then, substituting the best response into SW, one can obtain:

$$
s_{m}=\frac{(1+\alpha)\left[4 \delta c_{n}-c_{r}(3+\alpha)\right]-(1-\alpha)\left[4 \alpha p_{0}(1-\delta)+\delta(1+\alpha)\left(1-\delta+c_{r}\right)\right]}{(1+\alpha)[1+3 \delta+3 \alpha(1-\delta)]}
$$




$$
\begin{aligned}
S W^{M}= & \pi_{m}^{M}+\pi_{r}^{M}+\alpha\left(\int U_{n}^{n} d \theta+\int U_{n}^{r} d \theta\right) \\
& +(1-\alpha)\left(\int U_{r}^{n} d \theta+\int U_{r}^{r} d \theta\right) \\
& -s_{m}\left(q_{n}^{r}+q_{r}^{r}\right) .
\end{aligned}
$$

According to the second order partial derivative of social welfare with respect to the manufacturer subsidy, $s_{m}$, one obtains:

$$
\partial^{2} S W^{M} / \partial s_{m}^{2}=-[1+3 \delta+3 \alpha(1-\delta)] / 16 \delta(1-\delta)<0 .
$$

The social welfare $S W^{M}$ is strictly concave with respect to the manufacturer subsidy, $s_{m}$, and the government maximizes social welfare by setting an appropriate subsidy. Therefore, through the first-order condition of $S W^{M}$, with respect to $s_{m}$, one obtains the optimal values of the manufacturer subsidy.

\subsection{Model R: The government provides a subsidy to the recycler}

As having an important position in the CLSC, the retailer is responsible for the marketing activities of the new and remanufactured products. Therefore, the government expands the demand of remanufactured products through subsidy to stimulate the retailer's participation. According to the law in developed countries like Japan and the EU, original retailers should reprocess to deal with steel and other metal in waste batteries, as well as obtaining subsidies from governments to ensure obtaining a profit through selling $[21,35]$. Therefore, under this scenario of subsidizing the retailer, the profit functions of the manufacturer and retailer can be presented as follows:

$$
\begin{aligned}
\pi_{m}^{R}= & \left(p_{n}-c_{n}\right)\left(q_{n}^{n}+q_{r}^{n}\right)+\left(p_{r}-c_{r}\right)\left(q_{n}^{r}+q_{r}^{r}\right) \\
& -p_{0}\left(q_{r}^{n}+q_{r}^{r}\right), \\
\pi_{r}^{R}= & \left(p_{0}-b+s_{r}\right)\left(q_{r}^{n}+q_{r}^{r}\right) .
\end{aligned}
$$

Proposition 3. In Model $R$, the optimal decisions for the government subsidy is summarized as follows:

$$
s_{r}=\frac{4 \alpha p_{0}(3+\alpha)-(1+\alpha)(3+5 \alpha)\left(\delta-c_{r}\right)}{1+5 \alpha(2+\alpha)} .
$$

Proof. As shown in the above proof, the best response functions of the manufacturer and retailer are as:

$$
\begin{aligned}
& p_{n}^{R}\left(s_{r}\right)=p_{n}^{N}-s_{r}(1-\alpha) / 2(1+\alpha), \\
& p_{r}^{R}\left(s_{r}\right)=p_{r}^{N}-s_{r}(1-\alpha) / 2(1+\alpha), \\
& b^{R}\left(s_{r}\right)=b^{N}-s_{r}(3+\alpha) / 4(1-\alpha) .
\end{aligned}
$$

Then, substituting the best response into social welfare, one can obtain:

$$
\begin{aligned}
S W^{R}= & \pi_{m}^{R}+\pi_{r}^{R}+\alpha\left(\int U_{n}^{n} d \theta+\int U_{n}^{r} d \theta\right) \\
& +(1-\alpha)\left(\int U_{r}^{n} d \theta+\int U_{r}^{r} d \theta\right) \\
& -s_{r}\left(q_{n}^{r}+q_{r}^{r}\right) .
\end{aligned}
$$

According to the second order partial derivative of social welfare, $S W^{R}$, with respect to the recycler subsidy, $s_{r}$, one gets:

$\partial^{2} S W^{R} / \partial s_{r}^{2}=-(1-\alpha)[1+5 \alpha(2+\alpha)] / 16 \delta(1+\alpha)^{2}<0$.

Social welfare $S W^{R}$ is strictly concave, with respect to the recycler subsidy, $s_{r}$, and the government can maximize social welfare by setting an appropriate subsidy. Therefore, through the first-order condition of $S W^{R}$, with respect to $s_{r}$, the optimal values of the recycler subsidy are obtained.

The above discussion involves optimal pricing and subsidy decisions among manufacturer, recyclers and governments in different models. The equilibrium of which subsidy model reduces the negative effect of recycling obsolete products to the profit of the supply chain and facilitating the government to promote remanufacturing is provided as follows.

Corollary 3. The selling prices of new and remanufactured products, and the recycling price of obsolete products in different models are as follows:

$$
\begin{aligned}
& p_{n}^{R} \geq p_{n}^{N}=p_{n}^{M}, \quad p_{r}^{R} \geq p_{r}^{N} \geq p_{r}^{M}, \\
& b^{R} \geq b^{M} \geq b^{N} .
\end{aligned}
$$

Proof. By comparison of the selling price and the recycling price under different scenarios, one can obtain:

$$
\begin{aligned}
& p_{n}^{M}-p_{n}^{N}=0, \quad p_{n}^{R}-p_{n}^{N}=s_{r}(1-\alpha) / 2(1+\alpha), \\
& p_{r}^{M}-p_{r}^{N}=-s_{m} / 2, \quad p_{r}^{R}-p_{r}^{N}=-s_{r}(1-\alpha) / 2(1+\alpha), \\
& b^{M}-b^{N}=\left[p_{0}-s_{m}(1+\alpha)\right] /(1+\alpha), \\
& b^{R}-b^{N}=\left[p_{0}+s_{r}(3+\alpha)\right] /(1+\alpha) .
\end{aligned}
$$

Considering the subsidies for manufacturer $s_{m}$ and recycler $s_{r}$ are non-negativity, the selling price and recycling price in different models are as follows:

$$
\begin{aligned}
& p_{n}^{R} \geq p_{n}^{N}=p_{n}^{M}, \quad p_{r}^{R} \geq p_{r}^{N} \geq p_{r}^{M}, \\
& b^{R} \geq b^{M} \geq b^{N} .
\end{aligned}
$$

From the above comparison, the benefit of government subsidy is obvious. In Model M, the selling price of new 
products remains unchanged, that of remanufactured products decreases and the recycling price of obsolete products increased. The impact on selling price and recycling price is such that the manufacturer can improve market demand through a low-price strategy and save the production costs of remanufactured products. The recycler can also improve the profit margin. However, in collecting obsolete products from replacement consumers, the benefit for a CLSC is highest when the government subsidizes the recycler. Meanwhile, there is a direct effect on the selling prices of new and remanufactured products when the manufacturer sets a high price to offset the trading cost of remanufactured products. Hence, the implications of Corollary 3 form an interesting result in this paper. It shows that the more likely the agent is to being subsidized in the market, the lower the selling price and the recycling price is in the different models.

\section{Numerical analysis}

In this section, we provide some numerical examples to illustrate the impacts of consumer requirements and remanufactured preferences on the optimal pricing decision for a CLSC and varying government subsidies, as well as present the profits of manufacturers and recyclers. Based on the above analysis, the pricing, demand and profit under the different models can be prepared. Following assumptions from relevant literature $[17,36]$, the values of parameters in this paper can be adopted as follows:

$$
\begin{array}{ll}
c_{n}=0.8, & c_{r}=0.3, \quad p_{0}=0.1, \\
\alpha=0.4, \quad \delta=0.5 .
\end{array}
$$

\subsection{The optimal decisions, demand and profits in different models}

According to the above results in Table 1, the optimal solutions in different models are obtained and compared.

Table 1 shows the optimal solutions in different models under the values of parameter settings in this

Table 1. The optimal solutions in different models.

\begin{tabular}{cccc}
\hline $\begin{array}{c}\text { Decision } \\
\text { variable }\end{array}$ & $\begin{array}{c}\text { Model } \\
\mathbf{N}\end{array}$ & $\begin{array}{c}\text { Model } \\
\mathbf{M}\end{array}$ & $\begin{array}{c}\text { Model } \\
\mathbf{R}\end{array}$ \\
\hline $\boldsymbol{p}_{\boldsymbol{n}}$ & 0.886 & 0.886 & 0.923 \\
$\boldsymbol{p}_{\boldsymbol{r}}$ & 0.536 & 0.502 & 0.573 \\
$\boldsymbol{b}$ & 0.069 & 0.051 & 0.174 \\
$\boldsymbol{s}$ & - & 0.068 & 0.174 \\
$\boldsymbol{\pi}_{\boldsymbol{s c}}$ & 0.021 & 0.029 & 0.034 \\
$\boldsymbol{C} \boldsymbol{S}$ & 0.006 & 0.015 & 0.008 \\
$\boldsymbol{S} \boldsymbol{W}$ & 0.027 & 0.044 & 0.042 \\
\hline
\end{tabular}

paper. The solutions exemplify Propositions 1-3 and Corollaries 1-3. For example, it is interesting to find that the selling prices of new products in Model $R$ is set relatively higher than those of Model $\mathrm{N}$ and Model M. On the other hand, the selling prices of remanufactured products in Model $\mathrm{M}$ and Model $\mathrm{R}$ are, respectively, the lowest and highest, as well as that of Model N, which falls somewhere in the middle. Further, the recycling prices in Model $\mathrm{R}$ and Model $\mathrm{N}$ are, respectively, the lowest and highest. Also the price when the government subsidizes the manufacturer is somewhere in between. As for social welfare in each model, it is clear that the government subsidy improves the values of profit and consumer surplus. Comparing the different models, it is obvious that the values of the supply chain profit, consumer surplus and social welfare when the government subsidizes them, between the manufacturer and recycler are higher than those of Model N. Moreover, the subsidy to the manufacturer will transfer to the consumer surplus and to the recycler, which will transfer to overall profit. Therefore, the government should implement different subsidy policies based on the need for economic and social progress.

\subsection{The impact of relevant parameters on optimal decisions and social welfare}

By the above calculation, the impact of remanufactured preferences and primary consumer ratios on optimal pricing and social welfare in different models are shown in Figures 2-5.

As seen in Figure 2, it is found that the selling price and collecting price in three cases increase with the ratio of primary consumer increases, which is an inversely proportional relationship between the ratios of new and primary consumers. In other words, for the supply chain members whose strength of collecting and remanufacturing is weak, the collection price is smaller,

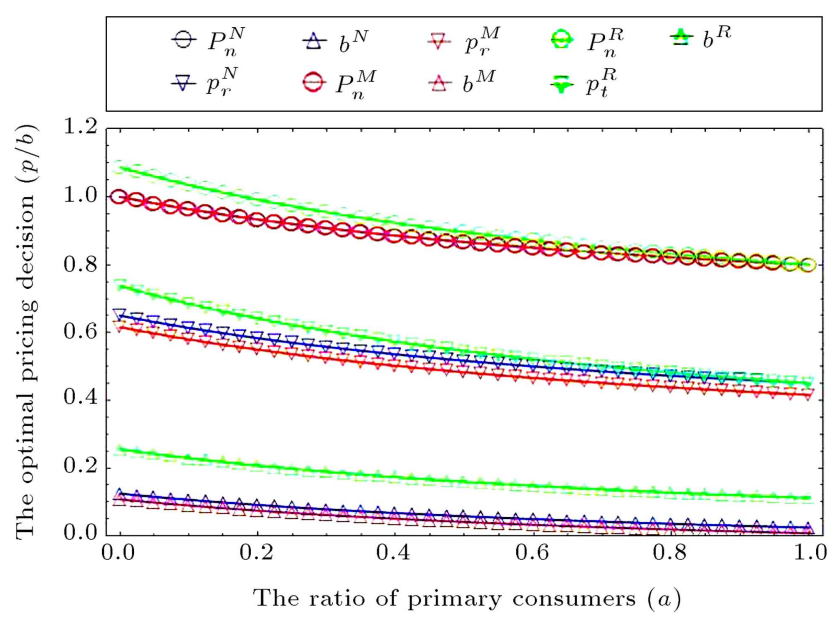

Figure 2. The impact of consumer's remanufactured preference on the optimal price. 


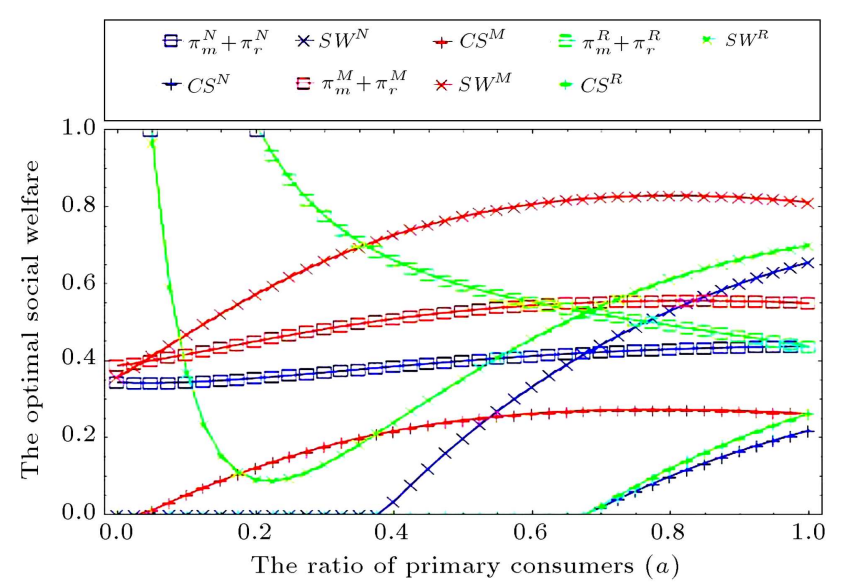

Figure 3. The impact of consumer's remanufactured preference on the social welfare.

ultimately reducing the cost of remanufacturing and the selling price of remanufactured products. Based on the competition between new products and remanufactured products, the selling price of new products also decreases. Comparing different subsidy models, when the government subsidizes manufacturer they are more likely to lower the selling price and collecting price. This is because the manufacturer is the most suitable operator to conduct market research, as well as being the closest to the market and to the consumers.

As shown in Figure 3, the consumer surplus in the three cases increases with the ratio of primary consumers. The consumer surplus when the government subsidizes the manufacturer is the largest; the non-subsidy situation is the minimum. The profit of the supply chain in the cases of non-subsidy and manufacture subsidy increases with the ratio of primary consumer increase, but that of the recycler subsidy has a negative correlation. And only when there is a larger ratio of primary consumers does the supply chain profit in the case of manufacturer subsidy become the maximum. Otherwise, that of the recycler subsidy is the maximum. In addition, the trend of social welfare is consistent with that of supply chain profit.

As seen in Figure 4, the selling price of new products is unrelated to the remanufactured preference. Also, the selling price and collecting price are the same in Model $\mathrm{N}$ and Model $\mathrm{M}$, when the government subsidy to the recycler is the maximum. Meanwhile, the remanufactured preference has a positive relationship with the selling price of the remanufactured product, and has a negative relationship with the collecting price, as well as that of Model M being the minimum, when the government subsidy to the recycler is the maximum. This is because when the consumer preference for remanufactured products increases, the acceptance of remanufactured products in the market gradually increases and the remanufactured product has more competitive advantage in market competition.

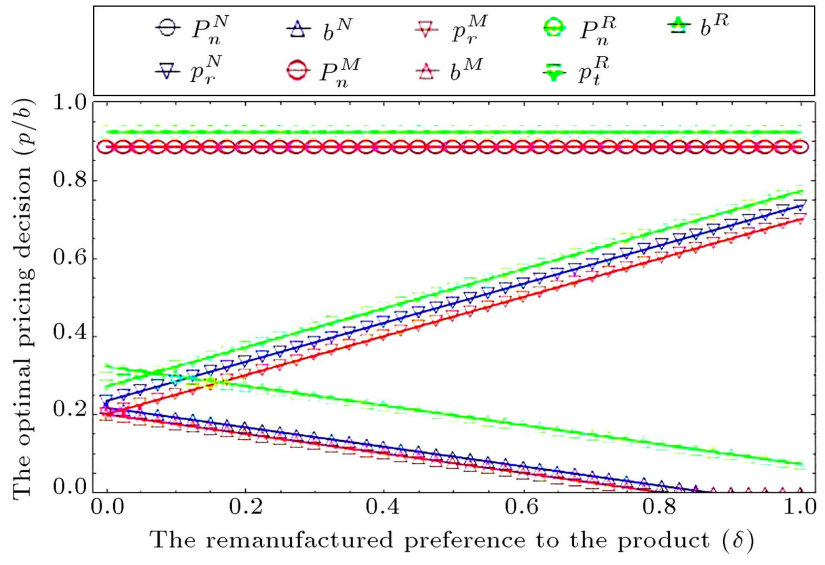

Figure 4. The impact of primary consumers' ratio on the optimal price.

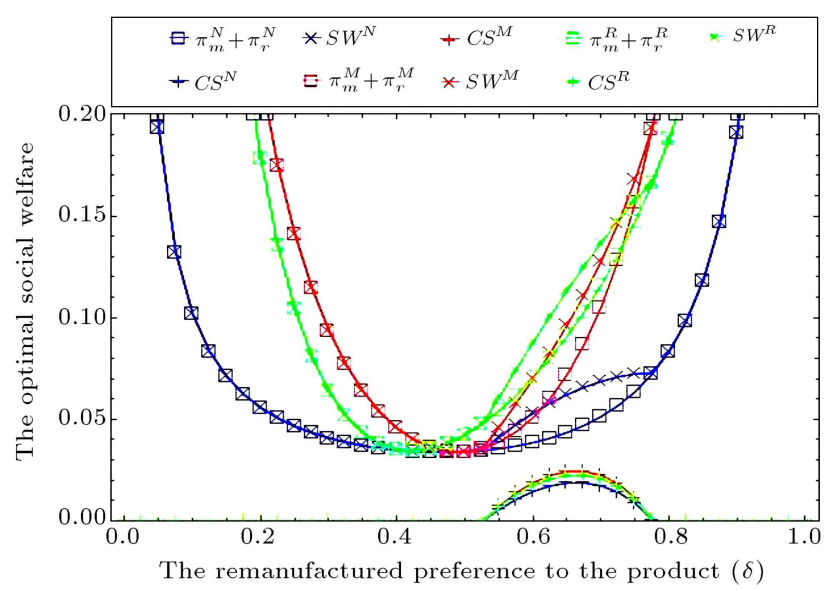

Figure 5. The impact of primary consumers' ratio on the social welfare.

As can be seen from Figure 5, when the remanufactured preference is relatively small, the supply chain profit and social welfare decline with consumer preference increases. Furthermore, the social welfare and supply chain profit reach maximum when the government offers subsidies. However, while the remanufactured preference is relatively large, supply chain profit and social welfare increase is maximum when consumer preference increases, and when the government subsidizes the recycler. Only when the remanufacturing preferences are within a certain range is the consumer surplus in the different models meaningful, and increase first and then decrease.

\subsection{The impact of relevant parameters on optimal subsidy}

By the above calculation, the impacts of remanufactured preferences and primary consumer ratios on optimal government subsidies in different models are shown in Figures 6 and 7 .

It can be seen from Figure 6 that with rising remanufactured preference, the optimal subsidy in Model 


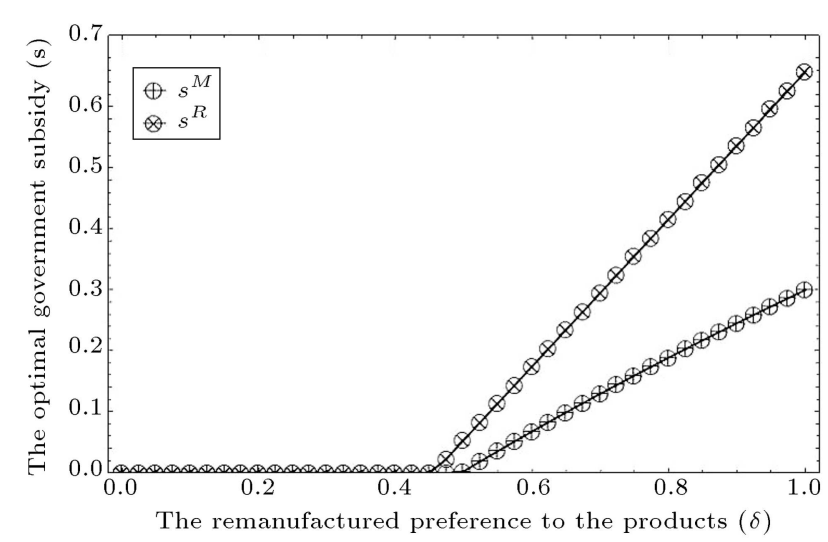

Figure 6. The impact of consumer's remanufactured preference on government subsidy in different models.

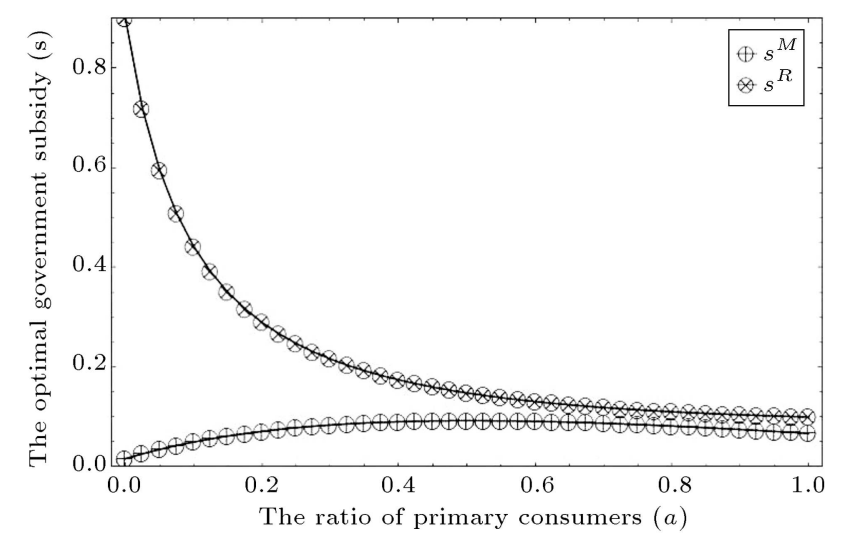

Figure 7. The impact of primary consumers' ratio on government subsidy in different models.

M and Model R increases gradually. Additionally, the figure also shows the government should invest more when subsidizing the recycler than that of the scenario of subsidizing manufacturers. The main reason is that the government subsidy to the CLSC comes from other industries, actually equivalent to social welfare and social recourse reassignment. Therefore, one can say that the subsidy to the manufacturer is a countermeasure to stimulating social demand, as well as the recycler in accelerating the pace of development in remanufacturing. Further, Figure 7 shows that as the ratio of primary consumers, the optimal subsidy declines gradually when government subsidizes the manufacturer. However, in the case with the ratio of primary consumers, the optimal government subsidy to the recycler has a gradual growth and then falls. It suggests that the government should provide subsidies to promote collecting and remanufacturing behavior, gaining support from manufacturing and the recycler easily in Model $M$ when the ratio of primary consumers is not very obvious. Meanwhile, the subsidy to the recycler becomes lower and lower as the market of the replacement consumer is already shrinking in size. From the perspective of government, in order to promote enterprises to develop collecting and remanufacturing, they have formulated a series of subsidy policies based on the market ratio between primary and replacement consumers.

\section{Conclusions}

A remanufacturing-preference product supply chain in a closed-loop setting is investigated, where the new products are produced by a manufacturer and the remanufactured products are collected by a recycler then resold to the manufacturer. Two segments of consumer are considered: primary consumers who can purchase new products or remanufactured products, and the replacement consumers who trade in obsolete products for new products or remanufactured products. This paper aims to compare the impacts of government policies with non-subsidy, manufacturer-subsidy and recycler-subsidy on the supply chain profit, consumer surplus and social welfare. According to comparison, we find that:

1. It is obvious that when the government subsidizes between the manufacturer and recycler that the values of the supply chain profit, consumer surplus and social welfare are higher than those of Model N. Moreover, the subsidy to the manufacturer will transfer to consumer surplus and to the recycler, which will transfer to overall profit;

2. Comparing different subsidy models, the government subsidies to manufacturers are more likely to make the selling price and collecting price lower. This is because the manufacturer is the most suitable operator to conduct market research, as well as being the closest to the market and to consumers;

3. Government subsidies improve social welfare, and the government should implement different subsidy policies based on the need for economic and social progress. From the perspective of government, in order to promote development of collecting and remanufacturing, they have formulated a series of subsidy policies based on the market ratio between primary and replacement consumers.

This paper has assumed that the trading price of obsolete products is fixed and an exogenous parameter. The models in this paper can be extended in several directions such as introducing competition between manufacturers and recyclers. Besides, the differentiated recovery quality of obsolete products can be studied further, as this paper has focused on horizontal and vertical cooperation between the manufacturer and recycler. 


\section{Acknowledgment}

We sincerely thank the anonymous editors and reviewers for their suggestions and comments. This research was supported by the National Natural Science Foundation of China (No. 71373157, 71403120).

\section{References}

1. Xu, L., Wang, C.X., and Zhao, J.J. "Decision and coordination in the dual-channel supply chain considering cap-and-trade regulation", J. Clean. Prod., 197, pp. 551-561 (2018a).

2. Xu, L. and Wang, C.X. "Sustainable manufacturing in a closed-loop supply chain considering emission reduction and remanufacturing", Resour. Conserv. Recyc., 131, pp. 297-304 (2018b).

3. Nazari, L., Seifbarghy, M., and Setak, M. "Modeling and analyzing pricing and inventory problem in a closed-loop supply chain with return policy and multiple manufacturers and multiple sales channels using game theory", Sci. Iran., 25(5), pp. 2759-2774 (2018).

4. Heydari, J., Govindan, K., and Jafari, A. "Reverse and closed loop supply chain coordination by considering government role", Transport. Res. D- TR. E., 52, pp. 379-398 (2017).

5. Wang, K., Zhao, Y., Cheng, Y., et al. "Cooperation or competition? Channel choice for a remanufacturing fashion supply chain with government subsidy", Sustainability., 6, pp. 7292-7310 (2014).

6. Cucchiella, F. and Adamo, I. "Technical and economic analysis of biomethane: a focus on the role of subsidies", Energ. Convers. Manag., 119, pp. 338-351 (2016).

7. Cui, L., Wu, K.J., and Tseng, M.L. "Selecting a remanufacturing quality strategy based on consumer preference", J. Clean. Prod., 161, pp. 1308-1316 (2017).

8. Chen, J.X., Liang, L., Yao, D.Q., et al. "Price and quality decisions in dual-channel supply chain", Eur. J. Oper. Res., 259, pp. 935-948 (2017).

9. Feng, L.P., Govindan, K., and Li, C.F. "Strategic planning: design and coordination for dual-recycling channel reverse supply chain considering consumer behavior", Eur. J. Oper. Res., 260, pp. 601-612 (2017).

10. Ji, J.N., Zhang, Z.Y., Yang, L., et al. "Comparisons of initial carbon allowance allocation rules in an $\mathrm{O} 2 \mathrm{O}$ retail supply chain with the cap-and-trade regulation", Int. J. Prod. Econ., 187, pp. 68-84 (2017).

11. Li, B., Zhu, M.Y., Jiang, Z.S., et al. "Pricing policies of a competitive dual-channel green supply chain", $J$. Clean. Prod., 112, pp. 2029-2042 (2016).

12. He, R.Y., Xiong, Y., and Lin, Z.B. "Carbon emissions in a dual channel closed loop supply chain: the impact of consumer free riding behavior", J. Clean. Prod., 134, pp. 384-394 (2016).

13. Li, X. and Li Y.J. "Chain-to-chain competition on product sustainability", J. Clean. Prod., 112, pp. 2058-2065 (2016).

14. Ferrer, G. and Swaminathan, J. "Managing new and remanufactured products", Manag. Sci., 52, pp. 15-26 (2006).

15. Debo, L., Totkay, B., and Wassenhove, V. "Market segmentation and product technology section for remanufacturable products", Manag. Sci., 51, pp. 11931205 (2005).

16. Atasu, A., Sarvary, M., and Van, L. "Remanufacturing as a marketing strategy", Manag. Sci, 54, pp. 17311746 (2008).

17. Shu, T., Peng, Z., Chen, S., et al. "Government subsidy for remanufacturing or carbon tax rebate: which is better for firms and a low-carbon economy", Sustainability, 9(1), pp. 1-22 (2017).

18. Atefeh, H., Jafar, B., and Mahdi, B. "A robust bi-level programming model to design a closed loop supply chain considering government collection's policy", Sci. Iran., 26(6), pp. 3747-3764 (2019).

DOI: $10.24200 /$ SCI.2018.20609

19. Nazari, L., Seifbarghy, M., and Setak, M. "Modeling and analyzing pricing and inventory problem in a closed-loop supply chain with return policy and multiple manufacturers and multiple sales channels using game theory", Sci. Iran., 25, pp. 2759-2774 (2018).

20. Savaskan, R., Bhattaharya, S., and Wassenhove, L. "Closed-loop supply chain models with product remanufacturing", Manag. Sci., 50, pp. 239-252 (2004).

21. Mitra, S. and Webster, S. "Competition in manufacturing and the effects of government subsidies", Int. J. Prod. Econ., 111(2), pp. 287-298 (2008).

22. Xiong, Y., Zhou, Y., Li, G., et al. "Don't forget your supplier when remanufacturing", Eur. J. Oper. Res., 230(1), pp. 15-25 (2013).

23. Atasu, A., Wassenhove, V., and Sarvary, M. "Efficient take back legislation", Prod. Operat. Manage., 18(3), pp. 243-258 (2009).

24. Hafezalkotob, A. "Competition of two green and regular supply chains under environmental protection and revenue seeking policies of government", Comput. Ind. Eng., 82, pp. 103-114 (2015).

25. Shao, L., Yang, J., and Zhang, M. "Subsidy scheme or price discount scheme? Mass adoption of electric vehicle under different market structures", Eur. J. Oper. Res., 262(3), pp. 1181-1195 (2017).

26. Ma, W., Zhao, Z., and Ke, H. "Dual-channel closedloop supply chain with government consumptionsubsidy", Eur. J. Oper. Res., 226, pp. 221-227 (2013).

27. Liu, H., Lei, M., and Deng, H. "A dual channel, 
quality-based price competition model for the WEEE recycling market with government subsidy", Omega., 59, pp. 290-302 (2016).

28. Hong, I. and Ke, J. "Determining advanced recycling fees and subsidies in "E-scrap" reverse supply chain", J. Environ. Manage., 92, pp. 1495-1502 (2011).

29. Wang, Y., Chang, X., Chen, Z., et al. "Impact of subsidy policies on recycling and remanufacturing using system dynamics methodology: a case of auto parts in China", J. Clean. Prod., 74, pp. 161-171 (2014).

30. Majumder, P. and Groenevelt, H. "Competition in remanufacturing", Prod. Operat. Manage., 10(2), pp. 125-141 (2001).

31. Webster, S. and Mitra, S. "Competitive strategy in remanufacturing and the impact of take-back laws", $J$. Oper. Manage., 25, pp. 1123-1140 (2007).

32. Dmity, K., Timur, N., and Anton, O. "Environmental taxes and the choice of green technology", Prod. Operat. Manage., 22, pp. 1035-1055 (2013).

33. Miao, Z., Mao, H., Fu, K., et al. "Remanufacturing with trade-ins under carbon regulations", Comput. Oper. Res., 89, pp. 253-268 (2018).

34. Aksen, D., Aras, N., and Karaarslan, A. "Design and analysis of government subsidized collection systems for incentive-dependent returns", Int. J. Prod. Econ., 119, pp. 308-327 (2009).

35. Jia, S., Yan, G., and Shen, A. "Dynamic simulation analysis of a construction and demolition waste management model under penalty and subsidy mechanisms", J. Clean. Prod., 147, pp. 531-545 (2017).

36. Ray, S., Boyaci, T., and Aras, N. "Optimal prices and trade-in rebates for durable, remanufacturable products", Manuf. Serv. Operat. Manage., 7(3), pp. 208-228 (2005).

\section{Biographies}

Lang XU received his $\mathrm{PhD}$ degree in 2018 from Shanghai Maritime University, where he is currently Assistant Professor in the College of Transport and Communications. He is also a visiting Professor of York University.

Qiaoyu Peng received his BS degree from Wuhan University of Technology, China, in 2018 and is currently a $\mathrm{PhD}$ degree student of Management Science and Engineering at Shanghai Maritime University. His research interests include supply chain and transportation.

Jihong Chen received his $\mathrm{PhD}$ degree in 2010 from Shanghai Maritime University, where he is currently a Professor in the College of Transport and Communications.

Chuanxu Wang received his $\mathrm{PhD}$ degree from Shanghai Jiaotong University in 1988, and is currently Professor in the School of Economics and Management at Shanghai Maritime University, China. 